\title{
Experience and reflections of using individual work histories and events of public sector doctors to unpack Human Resource Management policies and systems: Job histories as powerful method in Human Resource for Health research
}

Bhaskar Purohit ( $\nabla$ purohit.bhaskar@gmail.com )

Public Health Foundation of India https://orcid.org/0000-0002-7427-6371

Peter Stuart Hill

University of Queensland

Methodology

Keywords: Health workforce, Public sector doctors, Human Resource Management, job histories, implementation fidelity

Posted Date: January 9th, 2020

DOI: https://doi.org/10.21203/rs.2.20506/v1

License: (1) This work is licensed under a Creative Commons Attribution 4.0 International License. Read Full License 


\section{Abstract}

Background and methods: There is limited use of job histories in Human Resource for Health $(\mathrm{HRH})$ research. This paper presents authors' reflections of using job histories in HRH related research. In particular paper discusses how these can be useful method specifically to examine the implementation fidelity for health policy analysis of $\mathrm{HRH}$ and the strengths and limitations of this approach.

Methods: The context of this exploration is a multiple case study research project examining the implementation of HRH policies in public health sector in two Indian States-Sikkim and Rajasthan. As the doctors were the main subjects of the study, semi-structured interviews were conducted with 33 doctors to understand their experiences and interactions with the health department in relation to four key HRH management functions: recruitment, initial posting, transfer and promotions. The interview process revealed construction of work life related chronology by the doctors as a means of structuring their responses. This emerging pattern was adapted for the subsequent interviews to formalise it in form of job histories.

Key findings and reflection: Job histories constructed from the interviews gave rich descriptive accounts of doctors' experiences with the HRM systems, and also unravelled how HRM policies and systems operate, specifically in relation to adherence and dosage aspects of implementation fidelity, represented as narrative and quantitative accounts. For instance, job histories clearly allude non-adherence to posting rules and norms. Similarly, examination of the dosage aspect suggests variable application of HRH related policies and practices, delivered inconsistently across the doctors (applied to some and not to others or not applied consistently to the same doctor across his/her work career) or not applied as often as required. The organic and fluid nature of the job histories grounded in the qualitative data presents itself as a very powerful case in narrating rich job related stories and experiences of doctors. Additionally, it offers the flexibility to collect data in a more structured way potentially demonstrating useful chronological patterns and offering valuable insights into attempts to unravel the complexities and conflicts and in unpacking the rich individual experience, conflicts and tensions that public sector rural doctors confront in interacting with HRM policies and systems. Job histories can serve as a useful method for data collection in the area of Health Policy and Systems Research implementation, especially in relation to $\mathrm{HRH}$.

\section{Introduction}

Human Resource Health $(\mathrm{HRH})$ related policy and implementation analysis is a much neglected research area (1) (2). A systematic review of literature analysing health policy processes in Low-Middle Income Countries (LMICs) concludes very limited published literature in the area of $\mathrm{HRH}$ with even greater dearth of empirical analysis under the theme of 'policy and implementation' within $\mathrm{HRH}(2)$. 
The authors' previous experience in conducting HRH related research suggests there are gaps between HRH policy and its implementation, and the expectations of doctors. Health Policy and Systems Research (HPSR), specifically around HRM policies and systems suggests similar issues where such policies and systems are perceived to be bureaucratic, slow, sporadic, 'mission inconsistent', open to corruption, and disrupting career trajectories for doctors (3-7). Hence HRH related policy implementation and the methods that can examine it in public health sector is a critical that needs attention.

Job histories have been defined as "when the focus of the interview is the subject's career or professional trajectory and main work-related events they are referred to as work histories" (8). Job or 'work' histories have been used in disciplines such as hospitality (9), labour market analysis (10) and health sector, more specifically occupational and environmental health $(11,12)$. Some HRH related research also exist that use job histories as a method to examine the policy implementation $(5,6,13)$. However all of these papers discuss use of job histories as a pre-determined method for data collection with no discussion about how these could be adapted and represented in varied ways to meet specific objectives of $\mathrm{HRH}$ studies and the potential strengths and limitations of this approach.

With this backdrop, this paper explores how 'job histories' can be a useful method of data collection and representation in health policy implementation analysis, in particular analysing the 'policy implementation fidelity' (14) of HRH. The paper examines authors' experiences on how job histories evolved as a method in carrying out an $\mathrm{HRH}$ related policy research. The paper also examines and argues how the use of job histories as a method may be useful in unpacking the policy implementation gaps and how it serves as a powerful method in throwing light at rich individual experiences, conflicts and tensions that public sector rural doctors confront in interacting with the HRH policies and systems. These interactions, experiences, conflicts and policy implementation gaps are discussed in relation to three Human Resource Management (HRM) systems: recruitment, first posting and subsequent Posting and Transfer (PT). And finally the paper discusses some of the strengths and limitations of this approach in context of the current research.

While it is not vital (as scope of the paper is to demonstrate the usefulness of the method) and also beyond the scope of this paper to discuss detailed findings, but our reflections on usefulness of job histories cannot be fully justified unless some key examples from job histories are presented. Hence in order to demonstrate the usefulness of job history analysis in terms of what these can reveal in relation to the implementation fidelity and in unpacking the rich individual experiences, conflicts and tensions confronted by rural doctors in interacting with the HRH systems, we use four examples in the results section.

\section{Methods}

The context of this exploration is an embedded multiple case study research project examining the implementation of HRM policies in public health sector in two Indian States-Sikkim and Rajasthan. HRM systems (recruitment, P\&T and promotions) in two Indian states were defined as the cases. 
Content analysis of main policy documents and a total of 61 semi structured interviews were carried out in both the states, 28 with Kls and 33 with doctors. Of the total 61 interviews, 52 were conducted from February to April, 2018 while the remaining 9, all with Kls were conducted in October 2019 to follow up on questions that emerged from the previous interviews. Twenty eight interviews were conducted with the policy elites and other Kls (sixteen in state 1, eleven in state 2 and one from outside both the states) with an average interview time of around 32 minutes. This group comprised of policy elites such as health policy makers, health managers, administrative staff at state and district level, individuals representing doctors association or other relevant departments.

Thirty three interviews were done with doctors (fifteen in state 1 and eighteen in State 2) with an average interview time of 36 minutes. The doctors interviewed were employed either permanently or contractually, practicing either biomedicine or alternative systems of medicine- Ayurvedic, Yunani, Siddha and Homeopathy (AYUSH). As the doctors were the main subjects of the study, 'Job histories' were constructed from the 33 doctors' interviews to give a descriptive as well as a quantitative account of doctors' experience with the system and also the actual account of how HRM policies and systems operate. Doctors mainly from rural health centers (PHCs and $\mathrm{CHCs}$ ) were included to explore their perceptions and experiences of HRM related policies and systems. Purposive sampling was used to ensure the representation of regular and contractual doctors based on gender and type of system practiced (biomedicine and AYUSH).

This paper is drawn from our experiences of using the job histories constructed from the 33 interviews with doctors from the two study states. It is important to suggest here that detailed job history data was not collected from the first few interviews with the doctors. However the initial interview process revealed construction of work life related chronology by the doctors as a means of structuring their responses. This emerging pattern was adapted for the subsequent interviews to formalise it in form of job histories. Subsequently a simple job history format was developed using a simple set of quantitative questions used at the beginning of the remaining interviews.

Job histories were analysed using simple numbers, frequencies, percentages with use of graphical methods to demonstrate some of the patterns observed in the job histories. Framework Analysis (FA) approach using thematic coding was carried out to arrange, synthesise and analyse qualitative data using NVIVO 12.

Ethics approval was sought from the Ethics review teams at The University of Queensland (approval number 2017001666) and Indian Institute of Public Health Gandhinagar (IIPHG), India. Relevant study permissions were obtained from the Departments of Health in both the study states. Written consent was obtained prior to data collection and the personal data and transcripts were anonymized prior to analysis. There were three demurrals (all three were key informants) who were not comfortable with audio recording in which case oral consent was obtained and detailed interview notes were taken. All the interviews were transcribed and once the analysis process was over, de-identified. 


\section{Results}

The result section is organised into four examples that demonstrate interactions, experiences, conflicts and policy implementation gaps in relation to three Human Resource Management (HRM) systems: recruitment, first posting and subsequent Posting \& Transfer (P\&T). For the purposes of this paper, to demonstrate the variations possible within the data, we have purposively selected different sets of job histories from the two sites. The examples are not contiguous with each other and do not represent our complete findings.

\section{Example 1: What is recruitment in public sector and how long does it take?}

Health is a state responsibility in India, and each state has Public Service Commission (PSC) that is responsible for recruitment of permanent government employees. Recruitment through the PSC is very important to the employee, as it represents the official starting point of permanent service with the government. Employment and work experience with the health department prior to PSC recruitment (often under contractual, temporary or ad-hoc appointment) does not count towards any service related benefits like pension, promotions etc. Doctors appointed under contractual category are required to pass the PSC exam during their service, and PSC recruitment is considered the definitive starting point for government permanent employment. The main function of the PSC is to conduct examinations for appointment in state services and prepare a merit-cum-seniority list of doctors based on the date of the PSC examination and the marks scored. Due to PSCs being overburdened, sporadic and often lengthy gaps of several years between PSC examinations are a pervasive problem $(6,15)$. Clearly this has ramifications over career trajectories for doctors because doctors who pass the PSC have their seniority listed from that date (irrespective of the work experience with the health department prior to the PSC examination). The rules and orders by the Government suggest for promotion by merit or on the basis of seniority, but seniority being the most important factor (16). If two doctors pass the examination at the same time, then the one who scores more in the PSC evaluation is placed higher on the seniority list.

The graph below has been constructed from the job histories of eleven doctors, eight from Sikkim (Doctor 4-11) and three from Rajasthan (Doc 1-3) giving graphic insight into comparison between doctors' total service commitment and the portion (if any) recognised as permanent appointment.

As evident from the graph, the $11 \mathrm{job}$ histories are quite varied. The time gap between recruitment to government services (either contractual, ad-hoc or temporary) to permanent recruitment through the PSC varies from as little as 2 months to as long as 60 months (doctors 1-6). This missing bar for the two contractual doctors (doctor 10 and 11) suggests system inefficiencies. The PSC exam has not been offered in the past 10 years, and as result they have been continuing on temporary service for as long as 8-10 years. The missing bar for the three AYUSH doctors, however suggests that none have achieved permanent recruitment, despite 3-5 years' service. Sikkim state accepts AYUSH doctors to meet temporary service demands, but does not recruit these doctors in permanent positions, effectively creating a ceiling to their potential careers, with no opportunity for permanent recruitment, irrespective of their years of service with government. 
The graphic evidence highlights the variability in progression to permanent recruitment, attributable to the irregular availability of the PSC examinations, with its consequences for career trajectories of doctors, and the absence of an option to progress for AYUSH doctors in Sikkim state. Such career stagnation affects their motivation leading to high turnover rates.

"Our career progression is absolutely zero (laughs). Frankly speaking, you feel like you are stuck career wise. Other doctors have great avenues but for us there is no promotion. I have been working since 5 years and I know another AYUSH doctor who has been working since last 6-7 years ... A regular doctor would hardly resign but for NHM doctors (referring to all contractual doctors recruited through NHM), especially AYUSH, job quitting happens every now and then. Since they have been working since 5-6 years, they get fed up, no job security, nothing, so everybody who's working under NRHM, they are looking for something or the other like better opportunities or scope to study further... Again the new ones come and join the health department/NHM then leave... and the same cycle continues" (AYUSH 001)

\section{Example 2: What is an appropriate location for an initial posting?}

Job histories were analysed to determine the patterns of first posting for new recruits into rural services. As evident from the above figure, there appears to be no uniformity or consistency for the selection of first posting. It suggests that doctors may be posted to very rural $\mathrm{PHC}$ or to a rural $\mathrm{PHC}$ or to an urban District Hospital (DH) or even to the biggest hospital based at state headquarters. Recruits indicate hospitals are their first preference, rural PHCs their lowest preference. The job histories further suggest that the time spent at first post can significantly vary from 12 months to as long as 60 months and, depending upon whether a doctor considers the post as favourable or not, can have significant impact over their motivation.

The place of first posting and also time spent at first post is critical to doctors' career progression. Interviews with KIs and doctors suggest that a HRM expectation that most initial postings are in rural PHCs; three years (36 months) of rural service entitle doctors to a posting at the state/district level. The job histories clearly suggest that the norms for first posting and duration are not consistently applied across the doctors. The study participants described a pattern of unpredictability in first appointments, but attributed irregularities to some doctors using political patronage to influence the place and duration of their postings to their benefit, while marginalising others.

\section{Example 3: How long before a transfer and where?}

(a) What kind of health centres are doctors posted to during their career?

(b) Whether such posting durations adhere to P\&T policies or norms?

The job histories relating to transfer below aim to answer two critical questions: (a) What kind of health centres are doctors posted to during their career (b) Do such posting durations adhere to P\&T policies or norms? 
In terms of P\&T, there appear to be no established patterns for movement of doctors either in relation to: (a) frequency of transfers (minimum or a maximum time they spend at a post) (b) place of health centre transfer (with movements from urban to rural or rural to urban or a mix of the two).

Individual job histories also allow normative comparisons against the generic P\&T norms in civil service that suggests a recommended duration for each posting of at least 36 months (17) and preferably between 36-60 months (18). The minimum interval has been recommended in order to provide insulation to administrative officers and civil servants against political pressures from being too frequently transferred (17). As evident from the job histories, of the total 17 postings held across the four doctors, 12 (70\%) did not comply with the transfer norm (the bold figures in the table above suggesting the deviance).

\section{Example 4: How fluid or stable are transfers and do these comply with policies?}

An alternative way of representing the job histories for another set of selected doctors is given below. As evident from the figure, frequencies of transfers and posts held vary significantly for the selected doctors and such variations can range from as low 2.5 months to 132 months suggesting a great fluidity or stability when it comes to occupying a post. These job histories also demonstrate that of the total 20 posts held by 4 doctors, 14 did not comply with the generic P\&T rule of 36 to 60 months.

\section{Reflections And Discussion}

The main purpose of this paper was to examine how 'job histories' offer as a useful method of data collection and representation in health policy implementation analysis, in particular analysing of the 'policy implementation fidelity' and doctors' experiences with HRM policies and practices. In doing so several examples were presented that clearly show the interfaces between these and doctors' own expectations and experiences and its possible impact on their career trajectories. In this section we discuss some of our reflections of using job histories.

\section{Adapting job histories:}

During the qualitative interview process that probed on various aspects of doctors' job and their experiences about the same, it became quite apparent that the doctors were constructing a work life related chronology of their experiences and as a means of structuring their responses. The researchers saw this pattern emerging and adapted the subsequent interviews structure to formalise this pattern in form of job histories. The emerging patterns constructed from the doctors' interviews gave rich descriptive accounts of their experiences with the HRM systems and also unravelled how HRM policies and systems operate, represented as narrative and quantitative accounts in the examples above.

Several patterns relating to chronological events of job histories emerged from the interviews, hence inductive and deductive approaches were used to formalise these patterns. While in the inductive approach job histories emerged organically from interviews and were constructed, the deductive approach was guided through a relatively more structured way, allowing histories to be collected rather 
than constructed. Numbers, frequencies, percentages and graphical methods were used to demonstrate some of these patterns in the examples above.

There were however some methodological advantages and challenges in using job histories as either approach. Chronology of job history events generated through structured quantitative questions meant an uninterrupted and continual description of required details from the respondents. Although with the caveat of rich narrative information associated with each of such job history events missing at the time when these were actually described. Methodologically, it meant going back to each of these chronological events again to capture descriptive accounts.

Similarly relying solely on qualitative interviews to generate relevant information from job histories presented several methodological issues and challenges. For first, locating relevant information (specifically when it relates to dates and places of postings) became challenging for the researcher. Secondly with limitations of available time for interviews and the nature of qualitative interviews where the narrative accounts of individual experiences becomes so important, only a few important job history events may be discussed, either leaving other aspects and events of job histories only answered superficially or requiring a follow-up interview, if at all this could be done.

\section{Strengths of job histories:}

$\mathrm{HRH}$ related policy outcomes can be effectively achieved if such policies are implemented with 'policy implementation fidelity' (14). Implementation fidelity has two main aspects: adherence and dosage. Adherence is described as whether the policy or practice is delivered as it was designed or written' (19), while the dosage assesses whether the frequency and duration of the policy or practice is as intended (19). It is important to note that policies can be in form of written documents or may be implicit or unwritten (20). In the absence of policy documents, specifically in relation to P\&T, the current study relied on normative accounts of these policies to assess implementation fidelity using job histories. For instance adherence in the context of the research suggests that the norms in relation to posting in terms of place and duration are not followed. Similarly the dosage in context of the current research means that not all of the aspects of a $\mathrm{HRH}$ related policies and practices are delivered consistently across the doctors (applied to some and not to others or not applied consistently to the same doctor across his/her work career) or not applied as often as required as evident from the examples above.

Our experience of using job histories from the current research suggests that these can be robust and powerful in analysing the adherence and the dosage aspects of implememation fidelity. Further job histories may be particularly useful in getting deeper insights into doctors' experiences with the recruitment, P\&T, promotions policies and systems.

Job histories can offer great insight into attempts to unravel the complexities and conflicts in job related life of doctors in order to gain better understanding of doctors' interactions with the health systems. In particular such histories can be very useful in examining the adherence and dosage aspects of implememation fidelity. This can be done in several ways. For example, the chronology between doctors' 
job histories (vis-à-vis different HRM functions) and institutional policies and practices can be examined. Similarly job related chronologies of doctors between their counterparts may be examined for similarities and differences. And lastly such chronologies and patterns may be observed and compared within an individual to examine the consistency with which policy has been implemented and to examine how individuals feel about it.

One of the most unique things about the job histories is that they provide a structure that has the potential to extend the narrative to include much deeper stories as more columns are added to the job histories. For example, if more details are added to P\&T job histories, they can be very useful in illuminating other aspects such as issues around power (who decided about the transfers), whether individual requests were considered for transfer and how pervasive is the corruption.

\section{Best way to use job histories:}

Job histories can provide a prompt to generate qualitative as well as quantitative data, and can strengthen the triangulation of data derived from document review and interviews. For instance, data generated from job histories can further guide development of chronologies and patterns that may be observed and compared within an individual to examine the consistency with which policy has been implemented and to examine how individuals feel about it through the narrative accounts. Job histories thus generated can also offer great insight into attempts to unravel the complexities and conflicts in job related life of doctors in order to gain better understanding of doctors' interactions with the health systems. Hence job histories can complement and often strengthen the triangulation of data derived from document review as well as interviews. Considering this along with some of the limitations of job histories when used only as either a quantitative or qualitative method, we strongly recommend that job histories be used as a mixed method.

In terms of practical application beyond research, we recommend that the job history analysis in public health sector must have a practical use for policy planners and implementers. This would mean transition of job history analysis from a mere simple understanding of doctors' careers to a more nuanced analysis of challenges in relation to effective HRM that could ideally guide and feed into streamlining HR planning, policies and systems. If job history research can result into such practical implications such as HR planning and management, only then its real potential as a method is revealed.

\section{Limitations of job histories:}

Our experience of using life histories from the current research suggests a few limitations. The first relates to the issue of recall bias. While all the doctors' clearly remembered different aspects of their job related histories like place of first and subsequent postings, approximately how long they remained at each post, reasons and motivations for their movement from one health centre to the other and so on, there were some recall bias issues in specifying exact dates and durations for postings. This limitation was realised on analysing the job histories where it became evident that in a few cases the individual accounts did not translate to the aggregated accounts for events such as timing of PSC examinations. In 
some cases the time spent at each posting (during the professional career of a doctor) did not exactly add up to total years of work. An iterative process would allow the researcher to seek confirmation of specific dates from informants where this comes to light.

Another limitation relates to the significant details which are lost from individual job histories when data are analysed in aggregate form. For example as evident from example 3 , of the 17 postings (for 4 individuals), merely $5(30 \%)$ complied with the P\&T rule. However when these job histories are looked at in aggregate form in relation to the same P\&T rule, this number increases to $50 \%$. Similarly significant loss of data in relation to certain individual dimensions of job histories is seen when data are analysed in aggregate form for a particular aspect within an individual job history. While the job history of doctor 2 in that example shows that 5 of the 6 postings (83\%) did not comply with P\&T rule, averaging time in each post in the job history would suggest compliance. While aggregation of job histories data across the respondents as well as within an individual's job history may provide useful insights, there is a risk that in such an aggregation, the individual patterns and micro level details, individual stories, narrative and nuances may be lost.

\section{Conclusion}

Within the methodological realm the paper argues the usefulness of Job histories as a method for data collection in the area of Health Policy and Systems Research implementation, especially in relation to $\mathrm{HRH}$ research. The organic and fluid nature of the job histories grounded in the qualitative data presents itself as a very powerful case in narrating rich job related stories and experiences of doctors. Additionally, it offers the flexibility to collect data in a more structured way potentially demonstrating useful chronological patterns and offering valuable insights into attempts to unravel the complexities and conflicts and in unpacking the rich individual experience, conflicts and tensions that public sector rural doctors confront in interacting with HRM policies and systems.

\section{Declarations}

Ethics approval and consent to participate: Ethics approval was provided by the University of Queensland, Indian Institute of Public Health Gandhinagar, and India and study permission were obtained from the relevant Departments of Health.

Consent for publication: Not applicable

Availability of data and materials: Not applicable

Competing interests: None

Funding: The Public Health Research Institute (PHRI) and the department of Science and Technology (DST) for funding the research and IIPHG and PHFI for administering the funding 
Authors' contributions: BP conceived the study and carried out the data collection. BP and PH were involved in development of manuscript with significant contribution from $\mathrm{PH}$.

Acknowledgements: The Public Health Research Institute (PHRI), the TAG group, the department of Science and Technology (DST) for funding the research and IIPHG and PHFI for administering the funding. A special acknowledgement to the state health departments and the study respondents from Rajasthan and Sikkim. Also thanks to SRM University, Sikkim and the retired bureaucrat from Rajasthan for their support in seeking permission from both the states.

\section{Abbreviations}

Ayurvedic, Yunani, Siddha and Homeopathy (AYUSH).; CHC: Community Health Center; DH: District Hospital; HRH: Human Resource for Health; HRM: Human Resource Management; NRHM: National Rural Health Mission; P\&T: Posting and Transfer; PSC: Public Service Commission

\section{References}

1. Dussault G, Dubois CA. Human resources for health policies: a critical component in health policies. Hum Resour Health. 2003;1(1):1.

2. Gilson L, Raphaely N. The terrain of health policy analysis in low and middle income countries: a review of published literature 1994-2007. Health policy and planning. 2008;23(5):294-307.

3. Schaaf M, Freedman LP. Unmasking the open secret of posting and transfer practices in the health sector. Health policy and planning. 2015;30(1):121-30.

4. Sheikh K, Freedman L, Ghaffar A, Marchal B, el-Jardali F, McCaffery J, et al. Posting and transfer: key to fostering trust in government health services. Hum Resour Health. 2015;13:82.

5. Purohit B, Martineau T, Sheikh K. Opening the black box of transfer systems in public sector health services in a Western state in India. BMC Health Serv Res. 2016;16(1):419.

6. Purohit B, Martineau T. Issues and challenges in recruitment for government doctors in Gujarat, India. Hum Resour Health. 2016;14(1):43.

7. Collins CD, Hurst K, Omar MA. Staff transfer and management in the government health sector in Balochistan, Pakistan : problems and context. Public administration and development : an international journal of training, research, and practice : [a journal of the Royal Institute of Public Administration]. 2000.

8. Witter S, Namakula J, Alonso-Garbayo A, Wurie H, Theobald S, Mashange W, et al. Experiences of using life histories with health workers in post-conflict and crisis settings: methodological reflections. Health policy and planning. 2017;32(4):595-601.

9. Ladkin A. Life and work history analysis: the value of this research method for hospitality and tourism. Tourism Management. 1999;20(1):37-45. 
10. Dex S. Life and work history analyses : qualitative and quantitative developments. London; New York, N.Y.: Routledge; 1991.

11. Harris EC, Palmer KT, Cox V, Darnton A, Osman J, Coggon D. Trends in mortality from occupational hazards among men in England and Wales during 1979-2010. Occup Environ Med. 2016;73(6):38593.

12. Martin DJ, Chernoff RA, Buitron M, Comulada WS, Liang LJ, Wong FL. Helping people with HIV/AIDS return to work: a randomized clinical trial. Rehabil Psychol. 2012;57(4):280-9.

13. Kadam S, Nallala S, Zodpey S, Pati S, Hussain MA, Chauhan AS, et al. A study of organizational versus individual needs related to recruitment, deployment and promotion of doctors working in the government health system in Odisha state, India. Hum Resour Health. 2016;14:7.

14. Patterson M, Rick J, Wood S, Carroll C, Balain S, Booth A. Systematic review of the links between human resource management practices and performance. Health Technol Assess. 2010;14(51):1334, iv.

15. Jahan F, University B, Centre for Governance S. Public administration in Bangladesh. 2006.

16. Courseware on Common Administrative Issues, Reservation Rosters, Vigilance and Disciplinary Proceedings, (2012).

17. Iyer L, Mani A. Traveling agents: Political change and bureaucratic turnover in India. Rev Econ Stat Review of Economics and Statistics. 2012;94(3):723-39.

18. Revised guidelines of appointments and transfers of government employees/officers, (2005).

19. Dusenbury L, Brannigan R, Falco M, Hansen WB. A review of research on fidelity of implementation: implications for drug abuse prevention in school settings. Health Educ Res. 2003;18(2):237-56.

20. Buse K, Nicholas M, Walt G. Making Health Policy 2nd Edition ed: Mc Graw Hill: Open University Press 2012.

\section{Tables}

Table 1:

\begin{tabular}{|l|l|l|l|l|l|l|}
\hline Res & Category & $\begin{array}{l}\text { Type of } \\
\text { practice }\end{array}$ & $\begin{array}{l}\text { Place of first } \\
\text { post }\end{array}$ & $\begin{array}{l}\text { Request for } \\
\text { first Post }\end{array}$ & $\begin{array}{l}\text { Time spent at first post } \\
\text { (in months) }\end{array}$ & $\begin{array}{l}\text { Preferred } \\
\text { posting }\end{array}$ \\
\hline $\mathbf{1}$ & Regular & Biomed & DH & Similar & 72 & Yes \\
\hline $\mathbf{2}$ & Regular & Biomed & Remote PHC & Another & 36 & No \\
\hline $\mathbf{3}$ & Regular & Biomed & $\begin{array}{l}\text { State HQ } \\
\text { Hospital }\end{array}$ & Similar & 18 & Yes \\
\hline $\mathbf{4}$ & Contractual & AYUSH & Remote PHC & Another & $60 *$ & No \\
\hline $\mathbf{5}$ & Contractual & AYUSH & $\begin{array}{l}\text { Very remote } \\
\text { PHC Another }\end{array}$ & & 12 & No \\
\hline $\mathbf{6}$ & Contractual & AYUSH & DH & Similar & 20 & Yes \\
\hline
\end{tabular}

*Working at current place when interviewed 
DH: District Hospital; HQ: Head Quarters; PHC: Primary Health Center

\section{Table 2:}

\begin{tabular}{|c|c|c|c|c|c|c|c|c|c|c|}
\hline \multirow[t]{2}{*}{ Respondent } & \multicolumn{6}{|c|}{$\begin{array}{l}\text { Place of first and subsequent postings } \\
\text { (Time spent in months) }\end{array}$} & \multirow{2}{*}{$\begin{array}{l}\text { Service with } \\
\text { govt in months } \\
\text { (3) }\end{array}$} & \multirow{2}{*}{$\begin{array}{c}\text { No. of } \\
\text { transfer } \\
\text { (4) }\end{array}$} & \multirow{2}{*}{$\begin{array}{l}\text { Totals } \\
\text { posts } \\
\text { held } \\
(5)\end{array}$} & \multirow{2}{*}{$\begin{array}{c}\text { Mean time } \\
\text { spent at } \\
\text { post } \\
(3 / 5)\end{array}$} \\
\hline & $1^{\text {st }}$ & $2^{\text {nd }}$ & $3^{\text {rd }}$ & $4^{\text {th }}$ & $5^{\text {th }}$ & $6^{\text {th }}$ & & & & \\
\hline 1 & $\begin{array}{l}\mathrm{DH} \\
(60)\end{array}$ & $\begin{array}{l}\text { PHC } \\
(6)\end{array}$ & $\begin{array}{r}\text { PHC } \\
(6)\end{array}$ & $\begin{array}{r}\text { PHC } \\
(6)\end{array}$ & $\begin{array}{l}\mathrm{PHC}^{*} \\
\quad(4)\end{array}$ & - & 84 & 4 & 5 & 16.8 \\
\hline 2 & $\begin{array}{l}\mathrm{DH} \\
(18)\end{array}$ & $\begin{array}{l}\text { PHC } \\
(60)\end{array}$ & $\begin{array}{l}\text { PHC } \\
(12)\end{array}$ & $\begin{array}{l}\text { PHC } \\
(84)\end{array}$ & $\begin{array}{l}\text { PHC } \\
(18)\end{array}$ & $\begin{array}{l}\mathrm{DH}^{*} \\
(72)\end{array}$ & 264 & 5 & 6 & 44 \\
\hline $3 * *$ & $\begin{array}{l}\mathrm{DH} \\
(60)\end{array}$ & $\begin{array}{l}\text { PHC } \\
(60)\end{array}$ & $\begin{array}{l}\mathrm{DH} \\
(24)\end{array}$ & $\begin{array}{l}\text { PHC* } \\
(36)\end{array}$ & - & - & 180 & 3 & 4 & 45 \\
\hline 4 & $\begin{array}{l}\mathrm{DH} \\
(72)\end{array}$ & $\begin{array}{l}\mathrm{PHC}^{*} \\
(78)\end{array}$ & - & - & - & - & 156 & 1 & 2 & 78 \\
\hline Total & & & & & & & & 13 & 17 & 40.23 \\
\hline
\end{tabular}

*Continuing at the time of interview

Bold figures in the table indicate non-compliance to transfer rule of 36-60 months

DH: District Hospital; HQ: Head Quarters; PHC: Primary Health Center

\section{Figures}




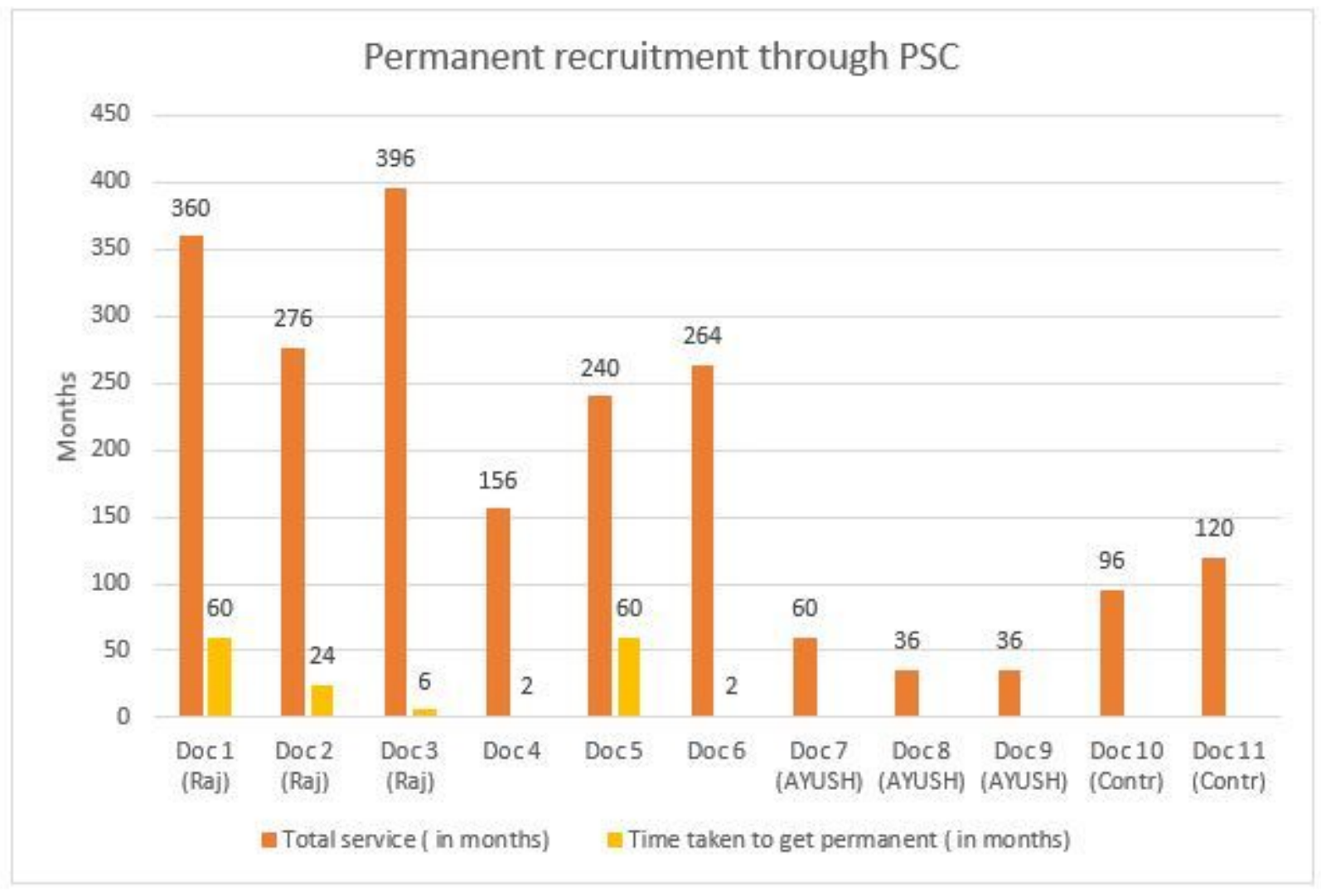

Figure 1

Government service and PSC permanent appointment

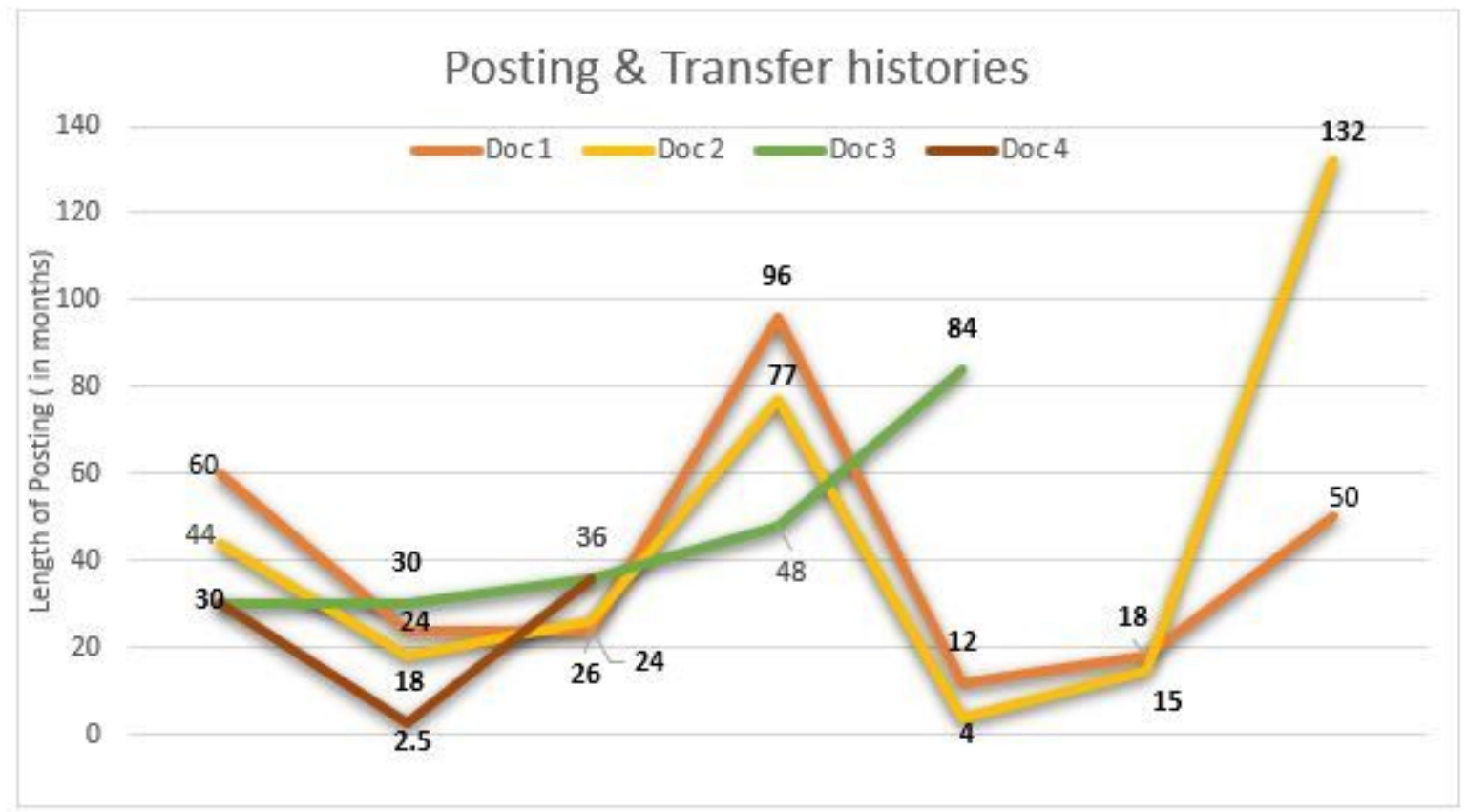

- The bold numbers indicate non-compliance to transfer rule

Figure 2 
P\&T histories and compliance with the rule

Page 15/15 